\title{
Sex cord stromal tumor of ovary masquerading as polycystic ovarian syndrome
}

\author{
Manisha Jhirwal*, Shashank Shekhar, Charu Sharma, Apoorva Tak
}

Department of Obstetrics and Gynecology, AIIMS Jodhpur, Rajasthan, India

Received: 21 March 2020

Accepted: 22 April 2020

\section{*Correspondence:}

Dr. Manisha Jhirwal,

E-mail: escatic.manisha@gmail.com

Copyright: () the author(s), publisher and licensee Medip Academy. This is an open-access article distributed under the terms of the Creative Commons Attribution Non-Commercial License, which permits unrestricted non-commercial use, distribution, and reproduction in any medium, provided the original work is properly cited.

\begin{abstract}
Virilization is a portentous sign that suggests the possibility of an ovarian or adrenal neoplasm. Diagnosis may be delayed in some patients due to nonspecific symptoms and overlapping symptoms with that of polycystic ovarian syndrome (PCOS). However, it must be remembered that PCOS usually causes mild to moderate elevation of serum testosterone with hirsutism whereas serum testosterone levels are many times elevated in cases of androgen secreting tumors and virilization is a norm. So high testosterone level with new onset virilization rule out PCOS. Authors are reporting two cases of Sertoli Leydig cell tumor despite their similar histopathology and equivalent levels of serum testosterone had a varied clinical spectrum of virilization.
\end{abstract}

Keywords: Hirsutism, Ovarian neoplasm, Polycystic ovarian syndrome, Sertoli Leydig cell tumor, Virilization

\section{INTRODUCTION}

Sertoli Leydig cell tumors (SLCT) of the ovary, account for less than $0.5 \%$ of all primary ovarian neoplasms. They are most commonly seen during the second and third decades of life, however may also present after menopause. SLCTs are unilateral in $98 \%$ cases and are confined to ovary.

They present with signs of excessive androgen production resulting in virilization like hirsutism, oligomenorrhoea, amenorrhea, breast atrophy, deepening of voice, male pattern baldness, acne, clitoral enlargement in one third of cases.

Usually patients present with few symptoms of virilization and are misdiagnosed as PCOS leading to delayed diagnosis. Sometimes, ovarian tumor could not be seen in grey scale ultrasound, hence advanced imaging technique like magnetic resonance imaging (MRI) should be used. ${ }^{1}$

\section{CASE REPORT}

\section{Case 1}

A 15-year-old girl presented to the gynecologic clinic with secondary amenorrhea for one year. Before presenting to study department, she was diagnosed as a case of polycystic ovarian syndrome by her previous treating physician.

Patient had a timely pubertal development and attained menarche at the age of 13 years. Patient also complained of deepening of voice for one year. On examination she had a clitoral length of $1.5 \mathrm{~cm}$. Her body mass index was $22.2 \mathrm{~kg} / \mathrm{m}^{2}$ and her modified Ferriman Gallway score (mFG) was 3.

Her total serum testosterone levels were $367.06 \mathrm{ng} / \mathrm{ml}$ (Normal reference range in females: 14-76 $\mathrm{ng} / \mathrm{dl}$ ) with normal DHEAS levels of $123.7 \mathrm{mcg} / \mathrm{dl}$ (normal reference range in females- $16-189.6 \mathrm{mcg} / \mathrm{dl})$. 
Ultrasound pelvis reported normal sized uterus and no adnexal pathology. With a strong clinical suspicion of androgen secreting tumor, MRI for adrenal glands and ovaries was done which showed left ovarian heterogeneously enhancing lesion of $3 \times 3 \times 2.4 \mathrm{~cm}$. Laparoscopic staging with left salpingo-oophorectomy was performed. It was stage $1 \mathrm{~A}$.

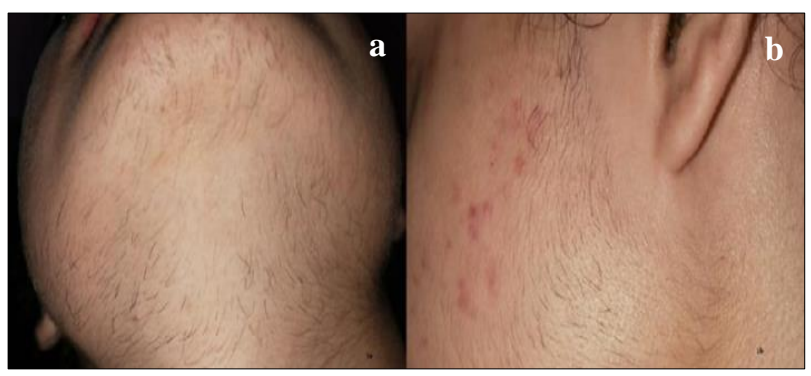

Figure 1: Excessive amount of dark, course hair on face in male pattern distribution.

On gross examination there was $3 \times 3 \mathrm{~cm}$ solid ovarian mass with intact capsule. On cut section multinodular and multi-cystic grey areas were noted. On H and E staining, microscopic areas of aggregates of eosinophilic Leydig cells in the stroma adjacent to Sertoli cell tubules were seen. On immune-histochemistry, tumor cells were immune reactive for WT1, Calretinin, Vimentin and focally for ER alpha and negative for Pan CK and EMA. Histopathological findings confirmed the diagnosis of Sertoli Leydig cell tumor of Intermediate differentiation.

Postoperative period was uneventful and patient was discharged on $3^{\text {rd }}$ day. Her testosterone levels normalized on day seven of the surgery (15.12 ng/dl). Pt is on a regular follow up.

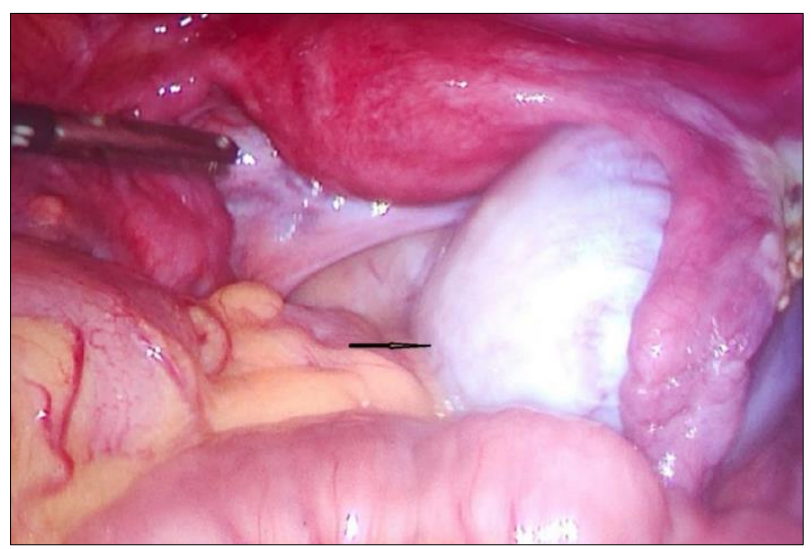

Figure 2: Per-operative greyish, smooth-surfaced, firm, and movable tumor of size $4 \times 4 \mathrm{~cm}$ in right ovary.

\section{Case 2}

A 21-year-old unmarried girl reported to study outpatient department with secondary amenorrhea for one and half years with excessive hair growth over chin, cheeks, upper lip and abdomen for last five months. She attained menarche at the age of 13 years with timely pubertal development.

She was previously diagnosed with PCOS and was taking combined oral contraceptive formulations. Initially she responded to estrogen and progesterone challenge test but later on there was no withdrawal bleeding. Authors revisited the history and noted deepening of voice. She had BMI of $23.4 \mathrm{~kg} / \mathrm{m}^{2}$.

On examination, secondary sexual characters were well developed but there was significant hirsutism of face and body (mFG score 24) (Figure 1a and 1b) and on local examination- clitoromegaly $(1.5 \mathrm{~cm})$. USG pelvis reported slightly enlarged right ovary $4.2 \times 3.2 \times 3.4 \mathrm{~cm}$.

Endocrinological evaluation revealed increased serum testosterone level (424 ng/dl), but DHEAS was within normal range $(181 \mu \mathrm{g} / \mathrm{dl})$. MRI for adrenal glands and ovaries was done which revealed right ovarian solid cystic lesion with predominantly solid component of size $3.5 \times 2.9 \times 3.1 \mathrm{~cm}$. The management involved laparoscopic staging followed by right salpingo-oophorectomy.

It was stage $1 \mathrm{~A}$. Intraoperatively, there was a $4 \times 4 \mathrm{~cm}$ solid right ovarian mass (Figure 2). The uterus and left ovary were grossly normal. The tumor capsule was intact.

On cut section, the right ovary was fleshy with solidcystic areas in it.

Histopathological examination of tumor revealed a Sertoli Leydig cell tumor with Sertoli cells in predominantly tubular pattern with Leydig cells in intervening stroma on immunohistochemistry, it was positive for Inhibin and Calretinin and negative for epithelial marker EMA.

Case 1 - serum testosterone- $367 \mathrm{ng} / \mathrm{ml}$, DHEAS- 123.7 $\mathrm{mcg} / \mathrm{dl}$, MRI adrenal and ovaries- left ovarian heterogeneously enhancing lesion of $3 \times 3 \times 2.4 \mathrm{~cm}$.

Case 2 - serum testosterone - $424 \mathrm{ng} / \mathrm{ml}$, DHEAS $181.02 \mathrm{mcg} / \mathrm{dl}$, MRI adrenal and ovaries- right ovarian solid cystic lesion with predominantly solid component of size $3.5 \times 2.9 \times 3.1 \mathrm{~cm}$.

Both the cases were investigated on the line of nonclassical $\mathrm{CAH}$ and other ovarian tumors. All investigations were within normal limit.

\section{Differential diagnosis}

Adrenal tumor and non-classical CAH - patient presented with menstrual irregularities, significant hirsutism, male pattern baldness. She was investigated on line of adrenal tumor and non-classical CAH. Her 17 hydroxyprogesterone and adrenocorticotropic hormone 
was normal, which ruled out adrenal tumor and nonclassical CAH.

\section{Treatment}

Case 1: Laparoscopic staging followed by left salpingooophorectomy.

Case 2: Laparoscopic staging followed by right salpingooophorectomy.

\section{Outcome and follow-up}

The preoperative elevated serum testosterone level declined to normal on day seven. Both the patients were being followed up on a regular basis. They had their menses after one month of surgery.

\section{DISCUSSION}

SLCTs of the ovary, account for less than $0.5 \%$ of all primary ovarian neoplasms. They are most commonly seen during the second and third decades of life, however may also present after menopause. SLCT's are unilateral in $98 \%$ cases and are confined to ovary. They present with signs of excessive androgen production resulting in virilization like hirsutism, oligomenorrhoea, amenorrhea, breast atrophy, deepening of voice, male pattern baldness, acne, clitoral enlargement in one third of cases. ${ }^{1}$ In the first case of SLCT, patient presented with amenorrhea and deepening of voice with no hirsutism. On the other hand, second case had amenorrhea, significant hirsutism and deepening of voice despite similar levels of serum testosterone. Information on the clinical behavior of SLCT, as well as its prognostic factors and optimal management, is limited due to the substantially low incidence of the disease. Diagnosis may be delayed in some patients due to nonspecific symptoms and overlapping symptoms with that of PCOS. However, it must be remembered that PCOS usually causes mild to moderate elevation of serum testosterone with hirsutism whereas serum testosterone levels are many times elevated in cases of androgen secreting tumors and virilization is a norm. So high testosterone level with new onset virilization rule out PCOS. ${ }^{2}$ Androgen secreting ovarian tumors are often embedded in ovary with polycystic appearance. These tumors may be missed on grey scale ultrasound such as in the index case and hence advanced imaging (MRI) methods can be utilized. It is shown that the sensitivity and specificity of MRI is better than ultrasound $78 \%$ and $100 \%$ respectively. ${ }^{3}$

SLCT are usually unilateral and present in early-stage. Therefore, fertility-sparing surgery is the preferred option in young women. The gold standard is surgical removal of the mass. Well-differentiated tumors are unilateral and have low malignant potential; therefore, unilateral salpingo-oophorectomy is adequate.

Hysterectomy and bilateral salpingo-oophorectomy, or full staging, which include thorough exploration of abdominal cavity, washing for cytological analysis, multiple biopsies, omentectomy, and pelvic or para-aortic lymph node sampling or dissection with or without adjuvant chemotherapy is the best treatment for patients who do not wish to spare fertility. The stage and degree of tumor differentiation are the most important prognostic factors for these patients. If patients have poor prognostic factors, adjuvant chemotherapy should be considered. ${ }^{4}$ After surgery, symptoms of defemination usually disappear. Two to four months after the surgery, menstruation begins and other symptoms disappear in order of their appearance but enlargement of clitoris may last for as long as 20 years.

Funding: No funding sources

Conflict of interest: None declared

Ethical approval: Not required

\section{REFERENCES}

1. Nam SM, Kim JW, Eoh KJ, Kim HM, Lee JY, Nam EJ, et al. A Novel clinicopathological analysis of early stage ovarian Sertoli Leydig cell tumors at a single institution. Obstet Gynecol Sci. 2017;60(1):39-45.

2. Conway G, Dewailly D, Diamanti-Kandarakis E, Escobar-Morreale HF, Franks S, Gambineri A, et al. The polycystic ovary syndrome: a position statement from the European Society of endocrinology. Eu J Endocrinol. 2014;171(4):P1-29.

3. Sarfati J, Bachelot A, Coussieu C, Meduri G, Touraine P. Study group hyperandrogenism in postmenopausal women. Impact of clinical, hormonal, radiological, and immunohistochemical studies on the diagnosis of postmenopausal hyperandrogenism. Eur J Endocrinol. 2011;165:77988.

4. Oliva E, Alvarez T, Young RH. Sertoli cell tumors of the ovary: a clinicopathological and immunohistochemical study of 54 cases. Am J Surg Pathol. 2005;29:143-56.

Cite this article as: Jhirwal M, Shekhar S, Sharma C, Tak A. Sex cord stromal tumor of ovary masquerading as polycystic ovarian syndrome. Int $\mathbf{J}$ Reprod Contracept Obstet Gynecol 2020;9:2616-8. 